\title{
Bronchopulmonary dysplasia and emphysema: in search of common therapeutic targets
}

Jacques R. Bourbon ${ }^{1,2,3 *}$, Olivier Boucherat ${ }^{4}$, Jorge Boczkowski ${ }^{1,2}$, Bruno Crestani ${ }^{5}$, Christophe Delacourt ${ }^{1,2,3}$

${ }^{1}$ Institut national de la santé et de la recherche médicale (INSERM), Unité 955-Institut Mondor de Recherche Biomédicale, Créteil, France

2 Université Paris 12, Faculté de Médecine, Créteil, France

${ }^{3}$ PremUP, Paris, France

${ }^{4}$ Centre de Recherche en Cancérologie de l'Université Laval, Centre Hospitalier Universitaire de Québec, L'Hôtel-Dieu de Québec, Québec, Canada

${ }^{5}$ Institut national de la santé et de la recherche médicale (INSERM), Unité 700, Université Paris 7 Denis Diderot, site Bichat, Paris, France

Corresponding author: Bourbon, J.R. (jacques.bourbon@inserm.fr)

Bronchopulmonary dysplasia of the premature neonate and emphysema of the adult lung are common diseases that are characterized by increased airspace size and respiratory insufficiency and that presently lack efficient treatment. Although the former leads to impaired alveolar development and the latter to alveolar destruction, they have striking similarities in their pathophysiology, including the precipitating effect of oxidative stress, sustained inflammation, enhanced apoptosis, proteaseantiprotease imbalance, elastic fiber deterioration, and altered microvascularization. This review aims to comparatively analyzing their molecular mechanisms to try identify common therapeutic targets. The recent discovery that alveolar developmental and maintenance programs share the same signal molecules and pathways, together with considerable increase in their understanding, have facilitated the development of common innovative strategies that have started to be tested in experimental models and pilot clinical studies. 


\section{Introduction}

Bronchopulmonary dysplasia and emphysema: two public health problems

Optimization of gas-exchange surface area is achieved by the subdivision of terminal airspaces of the lungs, called saccules, by very thin partition walls, the alveolar septa. These are lined by attenuated epithelium that allows respiratory gases to diffuse between air and the subjacent blood microvessels to which it is tightly apposed. Bronchopulmonary dysplasia (BPD) and emphysema are both characterized by pathologic evidence of deficit in alveolar number and increased airspace size, leading to reduction of exchange-surface-to-volume ratio and respiratory insufficiency. Presently, both conditions lack specific treatment to restore alveolar structure or even to prevent progression of the lesions. The complexities and difficulties in solving the problem arise from the fact that they are multifactorial diseases, with prolonged insults hampering the repair process.

BPD, which occurs postnatally either in very low birth-weight (VLBW) premature neonates as the result of multiple environmental injuries to the immature lung, or as a consequence of pre- or postnatal infection, is principally characterized by impaired alveolar and microvascular development (alveolar development is essentially postnatal in humans) [1]. BPD is the most common chronic respiratory disease in premature infants and affects about one third of those with VLBW [2].

Emphysema designates the permanent destruction of alveolar walls, which represents the alveolar component of chronic obstructive pulmonary disease It is a common disease that affects millions of people in the world and is most often a consequence of tobacco smoking, although in rare cases it is due to genetic defects $(3,4)$. Destructive lesions are associated with extracellular matrix (ECM) remodeling, including elastin disruption and increased collagen content [3].

\section{Why compare BPD and emphysema?}

BPD impairs alveolar formation, whereas emphysema results from progressive destruction of existing septa. However, both share a number of features in their pathophysiology: not only do they have some of the same precipitating factors, including oxidative stress, sustained inflammation, and protease-antiprotease imbalance, there is growing evidence of other similarities. It has thus been shown that the maintenance of adult alveolar tissue is placed under an active control mechanisms, that this maintenance program and alveolar growth share a number of pathways, and last, that numerous alterations in these pathways are common to both disorders.

The objective of this review is to comparatively analyze the known molecular mechanisms underlying both diseases with the goal of exploring possible common therapeutic 
approaches. This reflection is timely because the understanding of the pathophysiological mechanisms underlying BPD and emphysema has considerably progressed, and because knowledge about the control mechanisms of alveolar development and maintenance has tremendously increased in recent years. Nevertheless, the role the roles of some regulatory molecules and pathways have not yet been established precisely and have not been demonstrated to be rigorously the same in alveolar construct as in maintenance. These aspects are discussed with emphasis for the most promising potential targets.

\section{Alveolar development and alveolar plasticity in the adult lung}

Up to the formation of saccules, lung morphogenesis proceeds by dichotomous branching of the epithelial tubule. Formation of definitive alveoli (alveolarization or alveologenesis) involves a different process known as secondary septation (Figure 1). It consists in the surge, from the saccular wall, of crests (secondary septa), the growth of whichleads to saccule subdivision and enlargement of the exchange area. This seems to be triggered by elastic fibers deposited in the matrix of primary septa by a sub-class of interstitial cells designated myofibroblasts. Primary and secondary septa initially contain a double layer of capillary vessels. Their maturation, which is an integral part of alveolarization, involves the thinning of septa and the fusion of capillary vessels into a single central layer (Figure 1). Alveolarization implies integrated interactions between lung cell types and mutually regulated networks involving growth factors, transcription regulators and the ECM [5]. It may occur preor postnatally depending on the species.

The formerly accepted concept that the addition of new alveoli becomes impossible after capillary fusion has been challenged recently. Alveoli are actually added beyond maturation of septa in several rodent and primate species, and a recent investigation identified local duplication of the capillary network as the mechanism allowing new septa to be raised from mature septa [6]. This late alveolarization also accounts for adult lung plasticity, that is, the remodeling of mature lung architecture, including neoformation of alveoli for the adjustment of gas-exchange surface area to oxygen needs. This has been observed under different experimental conditions [7, 8], and suggests that in the future it might be possible to influence the reshaping of human lung structure.

\section{Comparative cell and molecular mechanisms of BPD and emphysema}

Lung histological features in BPD and emphysema

Initially described as an iatrogenic complication of neonatal respiratory distress syndrome (RDS), BPD was characterized by squamous metaplasia of airways, extensive fibrosis, and alternate zones of overdistended or collapsed alveoli. The disease has evolved considerably 
with the use of prenatal corticosteroids and surfactant therapy to prevent RDS, advances in ventilation techniques and survival in greater proportion of VLBW infants. Airway lesions have almost disappeared, whereas diffuse reduction of alveolar development has persisted. This "new" BPD is characterized by combination of alveolar simplification and dysmorphic microvascular network with minimal to moderate fibrosis [1].

There are two main morphological forms of emphysema [4]. Centrilobular emphysema is characterized by focal destruction of respiratory bronchioles and the central portion of acini surrounded by areas of grossly normal tissue, whereas panacinar emphysema involves alveolar destruction in a quite uniform manner. In both forms, alveolar wall destruction and permanent airspace enlargement are accompanied by elastin fragmentation and paucity of blood vessels. Fibrosis is generally absent.

\section{The role of oxidative stress}

Although oxygen supplementation is no longer considered as an absolute requirement to develop BPD, it remains routine practice in neonatal intensive care and contributes to lung injury. A number of markers of increased peroxidation have been found in tracheal effluent from neonates who later developed BPD and have been shown to correlate with the occurrence of the disease, which emphasizes their role as injury initiators (9). Premature infants are all the more exposed because antioxidant defense mechanisms mature late in pregnancy. Importantly, hyperoxia alone is sufficient to mimic most of the pathologic findings of BPD, including impaired septation, in neonatal animals from various species, even in the absence of premature delivery (reviewed in Ref. [5]). This involves reduced expression levels of various mediators known to have crucial roles in alveolar septation [5, 10-12].

Epithelial injury by free-radical oxidants present in cigarette smoke or produced by lung cells are also believed to have a prominent role in the pathophysiology of COPD. Enhanced 4-hydroxy-2-nonenal (4-HNE)-modified proteins, which reflect lipid peroxidation, were found in airway cells, alveolar cells, and polymorphonuclear neutrophils (PMNs), and were shown to correlate with severity of the disease [13]. Another oxidative stress marker, 8-isoprostane, was increased about twofold in COPD smokers compared with healthy smokers, who had themselves over twofold higher levels than nonsmokers [14]. A decrease in antioxidant systems, particularly the powerful heme oxygenase-1 (HO-1), was also described in severe COPD (15).

\section{The role of inflammation}

Pulmonary inflammatory response has a central role in the etiology of both diseases $[4,16]$. In BPD, inflammation resulting from mechanical ventilation, oxygen toxicity, or pre- or postnatal infection leads to much higher and persisting numbers of PMNs and macrophages 
in bronchoalveolar lavage (BAL) fluid [16]. Blocking the influx of PMNs prevented hyperoxiainduced developmental disorders in neonatal rats, suggesting that PMNs have a crucial pathogenic role [17). PMN and macrophage infiltration has similarly been evidenced in the emphysematous lung of smokers [3, 4].

Recruitment of neutrophils results from considerably increased concentrations of a variety of pro-inflammatory chemotactic and chemokinetic factors in BPD [16] as well as in COPD/emphysema [4], whereas anti-inflammatory cytokines are decreased [18, 19]. However, some differences might exist between the diseases. The pro-inflammatory cytokines tumor necrosis factor- $\alpha$ (TNF- $\alpha$ ), interleukin (IL)-1, IL-6, and IL-8 are increased in both diseases, but IL-17 has been reported to have a role in COPD only [4].

\section{Protease/anti-protease imbalance and ECM remodeling}

The observations that (i) emphysema can be induced by tracheal elastase instillation, (ii) $\alpha 1$ antitrypsin (an antiprotease) familial deficiency can lead to early-onset emphysema and (iii) $\alpha 1$-antitrypsin deficiency can be induced by cigarette smoke led early researchers to postulate that protease-antiprotease imbalance is a leading cause in emphysema. Soon after, this was postulated in BPD also.

Increased BAL levels of neutrophil-elastase and cathepsins (lysosomal proteases) have indeed been found in BPD [20]. Although increased activity of these enzymes has also received support in emphysema, the extent of lung destruction appears relatively independent of neutrophils in the latter and is instead directly related to the number of alveolar macrophages [21] the proteolytic activity of which is essentially mediated by matrix metalloproteinases (MMPs). Increased BAL concentration and increased macrophage and tissue expression of MMPs 1, 2, 9, and 12 have been found in patients with emphysema [22]. The absence of emphysema-like phenotype in MMP-12-deficient mice exposed to cigarette smoke supports a crucial pathogenic role for this MMP [23].

Imbalance between MMPs and their natural tissue inhibitors (TIMPs) in BAL has also been repeatedly reported in BPD. Low MMP-2 and increased MMP-9 activities [24], and high MMP-9:TIMP-1 ratio [25] have been associated with development of BPD. The role of MMP9 in BPD pathophysiology is controversial, however, because MPP- $9^{-/-}$mouse pups have been reported to present milder pulmonary effects of hyperoxia [26], but conversely to have worsened IL-1-induced lung disease [27]. A noteworthy difference between diseases resides in the presence of sustained predominant MMP activity in emphysema, whereas in BPD, after the initial destructive phase when high MMP activity predominates, the following repair phase is characterized by predominant TIMP activities, which favors ECM accumulation. 
Importantly, MMPs also have an essential role in normal alveolarization. Thus, activity of membrane type $1 \mathrm{MMP}$ (MMP-14) is absolute requirement for septation [28]. The related MMP-16 has recently been involved also, and is reduced in experimental models of BPD [29]. However, their mechanism(s) of action remain(s) imperfectly understood.

\section{Apoptosis and cell senescence}

In both diseases, signals resulting from oxidative stress, inflammation, and protease/antiprotease imbalance with subsequent matrix degradation converge toward cell damage and promotion of apoptosis of epithelial cells, and subsequently of endothelial cells $[30,31]$. However, the elevated number of apoptotic cells in emphysema has been suspected to result from impaired clearance of apoptotic cells rather than increased rate of apoptosis.

Ceramide, a lipid-signaling molecule that favors recruitment of signaling molecules for transducing stress-related signals is a mediator that might link leading causes with apoptosis. Recently, upregulation of ceramide was shown to cause emphysema in mice through the promotion of apoptosis, and the inhibition of ceramide synthesis was found to prevent experimental emphysema. Furthermore, the fact that human emphysematous lungs exhibit significant ceramide expression levels underscores this molecule as an interesting target to prevent airspace enlargement [32]. Investigation is nevertheless needed to further evaluate its value, and it is not known whether it is involved in BPD.

Cell senescence, a state of permanent growth arrest that leads to enlarged, flattened, and granular cell morphology with specific labeling features, might also contribute to emphysema. Recent studies have evidenced both replicative senescence, which depends on the number of times a cell population divides, and accelerated senescence secondary to exposure to different kinds of stress in all parenchymal cells of patients with emphysema [33].

\section{Elastic fiber destruction and disrupted assembly}

The elastic fiber is issued from the crosslinkage of tropoelastin by lysyl oxidase (LOX) and related enzymes on a scaffold of microfibrils (fibulins, fibrillins). Expression of components and enzymes must be coordinated so that the correct temporal sequence of assembly can be followed. This represents a major difficulty in the perspective of restoring elastic fibers, because in the adult lung, elastogenesis most often results in the production of elastin that does not organize into functional 3D fibers [34].

In BPD and models, increased excretion of elastin degradation products, desmosines, has been shown [35], and despite increased overall elastogenesis, there is evidence for disordered deposition of septal elastin, with paucity of elastic fibers that display abnormal structure and fail to locate at the tip of growing septa [35,36]. By contrast, elastic lamellae of 
blood vessels appear normal [36]. Mechanical ventilation, a triggering factor of BPD, has been found to uncouple synthesis and assembly of elastin in newborn mice, which might in turn participate to septation failure [37].

In contrast to normal lung in which elastin is exceedingly stable, emphysema is associated with elastin degradation and desmosine excretion proportional to lung function decline [38]. Elastic fiber structure is altered with fragmented appearance (3), which is reminiscent of BPD. Elastin degradation is therefore a common feature to BPD and emphysema, and although elastin synthesis is present, elastic fiber assembly seems to be disrupted in both conditions.

Using genetically modified mouse strains that express elastin at different levels, it was recently shown that not only lung development was adversely affected in mice with lowest levels, and further, that animals with intermediate levels, although initially developing normal alveoli, developed worse emphysema than mice with normal levels when exposed to cigarette smoke [39]. An emphysema-like phenotype has also been described in mice lacking LOX [40], fibrillin-1 [41] or fibulin-5 [42]. Deficient elastogenesis therefore seems to predispose to emphysema and to increase susceptibility to smoke injury.

In addition to elastic fiber destruction, collagen degradation products, especially proline-glycine-proline peptide, have important roles in COPD pathogenesis and might represent a new target for prevention of emphysema [43].

\section{Impaired microvascular development and maintenance}

Normal pulmonary function implies the coordinated development of alveolar epithelium and capillaries [44]. This requires correct spatial and temporal expression of angiogenic factors, primarily vascular endothelial growth factor (VEGF), which is principally produced by alveolar epithelial type II cells. Postnatal inhibition of VEGF-receptor (VEGFR) in newborn rats or mice simultaneously impaired vascular growth and alveolar septation [45], thus evidencing the dependence of alveolarization upon normal angiogenesis. Alveolar cell apoptosis and air space enlargement following VEGFR blockade [46] or inducible lung-targeted deletion of VEGF [47] in adult animals highlighted their involvement in the lung maintenance program also. Consistently, reduced expression of VEGF and VEGFR2 was demonstrated in the emphysematous lung [48].

The BPD lung exhibits dysmorphic microvessels embedded in thickened alveolar walls [49]. The previously proposed paradigm that microvascular growth arrest due to decreased angiogenic mediators [49] is a major pathogenic factor may not be completely accurate, however, since marked angiogenesis has been reported in long-term ventilated infants [50]. A number of data nevertheless support the view that angiogenesis is dysregulated. 
Determination of VEGF levels in tracheal aspirates has led to conflicting data. In fact, changes appear to be dependent on the timing of measurements, since an initial spike followed by a decline and then a subsequent rise have recently been described [51]. Consistent with the presence of, at least transient, VEGF decrease in BPD infants, endotoxin exposure in lambs [52] or mechanical ventilation with supplemental oxygen in mice [53] reduced pulmonary VEGF and VEGFR2 expression. Reciprocally, exogenous VEGF improved alveolarization in hyperoxia-exposed newborn rats [54]. This illustrates its therapeutic potential, although it should be used cautiously since VEGF excess may be detrimental for lung development $[51,55]$.

Other factors appear to be involved in complex interrelationships leading to angiogenic disorders of BPD. Elevated levels of the anti-angiogenic mediator endostatin in tracheal aspirates from infants with BPD [56] suggest that imbalance between pro- and antiangiogenic factors may account for disturbed angiogenesis. Last, endoglin, a transforming growth factor $\beta$ coreceptor that was previously implicated as an important regulator of angiogenesis in various neoplastic and nonneoplastic conditions, and angiopoietin 2, a complex regulator of vascular remodelling that mught induce both vessel sprouting and vessel regression depending on VEGF availability and that seems to be implicated in hyperoxia-induced cell death [57], are also both increased in BPD [58, 59] and may be involved in microvascular dysangiogenesis. There is thus far no report of similar changes in emphysema.

Figure 2 schematically integrates the causes and pathophysiological mechanisms involved in the occurrence of BDP and emphysema. Similarities and differences in pathological mechanisms are recapitulated in Table 1. In addition, the fact that in various genetically engineered mouse models, disturbed alveolarization was followed by later occurrence of emphysema allows one to raise the assumption of a predisposition to develop emphysema acquired in infancy. Supporting this view, young adult survivors of BPD may be left with residual structural and functional lung abnormalities, including emphysema [60].

\section{Therapeutic implications}

Targeting oxidative stress, inflammation and proteases

Lowering oxidative injury and inflammation has been attempted in BPD and COPD with mitigated results. Corticosteroids lower inflammatory reaction in the postnatal lung, but because of their severe deleterious neurological side effects, they must be used warily. However, a recent report found that entirely avoiding the use of corticosteroids increased the incidence of BPD [61]. Antioxidants, exogenous anti-oxidant enzymes, mast-cell stabilizers, 
and $\alpha 1$-proteinase inhibitors displayed no clinical benefit. Although nitric oxide (NO), which is both a factor with anti-inflammatory properties and a downstream effector of VEGF, improved alveolarization in experimental BPD [62], discrepant findings have been reported for inhaled NO: reduced death and BPD rates were reported in mildly sick preterm infants but, conversely, worsening outcome was reported in very ill VLBW infants [63]. Pentoxifylline, a peripheral vasodilator with anti-inflammatory effects, reduced the risk of BPD by $23 \%$ in a pilot study [64]. Blocking the CXC chemokine receptor CXCR2 has been shown to reduce oxygen-radical formation, to prevent neutrophil influx, and to preserve alveolarization in hyperoxia-exposed newborn rats [65].

Several approaches to restore antioxidant defenses in COPD or emphysema have been developed in experimental models (Table 2). Curcumin [66], statins [67, 68] and adenovirusmediated expression of HO-1 [69] have been successfully used to restore HO-1 levels and attenuate emphysema in mice.

Other potential targets are phosphodiesterases (PDE), the enzymes that degrade the second messengers cyclic adenosine and guanosine monophospate (cAMP and cGMP). The latter, among a variety of actions, exert inhibitory effects on many inflammatory cells. Two PDE4 inhibitors were recently reported to prolong survival and to reduce alveolar fibrin deposition, lung inflammation, vascular leakage, and protein efflux in BAL in preterm rats exposed to hyperoxia [70], although restoration of alveolarization failed and overall growth was markedly reduced [71]. Other PDE4 inhibitors attenuated smoke-induced emphysema in mice, through reduction of macrophage density, prevention of MMP-12 increase, and protection against apoptosis [72, 73]. PDE5 inhibition preserved alveolar growth and angiogenesis in hyperoxia-induced injury in rat pups [74].

Last, protease inhibition revealed preventing effects in animal models of emphysema [75, 76]. These different trials are summarized in Table 2. Considering the adverse side effects sometimes observed, they call for further investigation.

\section{Retinoids for the prevention and treatment of BPD and emphysema}

Numerous studies have underscored the key role of retinoic acid (RA), a vitamin A derivate, in alveolarization. Whereas RA increased alveolar number in newborn rats [77], deletion of RA receptors (RARs) resulted in disrupted alveolar formation [78]. Whereas corticosteroids accelerate microvascular fusion and block septation, RA prevents these effects, which suggests regulatory role of the latter in early mechanisms of alveolarization and of corticosteroids in the later maturation step.

The therapeutic value of retinoids is supported by clinical and experimental findings. In VLBW infants, low plasma retinol represents a predictive factor for developing BPD [79]. Likewise, inverse relationship between plasma retinol and the emphysematous decay of lung 
function indicated a role in alveolar maintenance [80]. Exogenous RA partially restored alveolar architecture in rats and mice with failed septation induced by various means [81-83], as well as in elastase-induced emphysema [84]. However, other investigations performed in rodents [85] or primates [86\} have conversely reported an absence if effect.

A recent meta-analysis of clinical trials of vitamin A supplementation showed modest reduction of BPD rate and morbidity in VLBW infants [87]. In emphysema, despite the numerous encouraging experimental data, no definitive clinical benefits of RA treatment have been observed in pilot studies [88]. The RA isoform used, dosage and drug pharmacokinetics are certainly major issues [89]. Moreover, the expression of Cellular RABinding Protein 2 (CRABP2), which modulates binding to RARs and transcriptional activity, is decreased in patients with emphysema. This was in turn responsible for a decrease of RAinduced elastin synthesis by lung fibroblasts, suggesting that insufficient CRABP2 could account in part for the lack of clinical benefits of RA treatment [90]. Lastly, in experimental pneumonectomy, RA failed to increase alveolar surface area per lung volume despite enlargement of septal tissue and capillary volume in remaining lung, including reinitiation of double capillary layers [91]. This distortion clearly indicated that other stimuli are required simultaneously for induction of harmonious septal growth.

\section{Role and potential therapeutic value of growth factors}

In addition to VEGF, which is considered above, various growth factors are involved in the control mechanisms of alveolarization, most especially platelet-derived growth factor $A$, which is necessary for myofibroblast migration and proper location [92], hepatocyte growth factor (HGF), the inhibition of which reduced alveolarization[(93], and fibroblast growth factor (FGF) signaling through FGF receptor (FGFR) 3 and FGFR4, which are simultaneously required for septation [94]. Several FGF ligands could be involved in septation, including FGF18, the expression of which peaks during septation [95] and was decreased by hyperoxia [12]. FGF18 and FGF2 were found to inversely control the expression of elastic fiber components in myofibroblasts [95]. Although FGF7 (or keratinocyte growth factor) binds another FGFR, high FGF7 concentrations in tracheal effluents from premature infants predicted the absence of BPD [96], which might relate to the protective properties of this factor for alveolar epithelium. Last, fibroblasts isolated from human emphysematous lung have been found to present markedly reduced basal production of HGF and lowered production of FGF7 in response to stimuli [97].

Supplementation of a variety of growth factors, including VEGF, HGF, and FGF7, has been attempted in models of BPD and emphysema [51, 54, 98-10] (Table 2). Because, in addition to its erythropoietic functions, erythropoietin (EPO) is an endothelial cell mitogen, its effects have also been explored [83] (Table 2). Findings suggest therapeutic potential, 
although trials have not yet left the field of animal investigation and negative results have sometimes been obtained. Moreover, limitations to the therapeutic use of growth factors reside in the risk that some might induce fibrosis and enhance the risk of tumorigenesis. Senescence of fibroblasts in emphysema represents another difficulty that might not necessarily be overcome by pharmacological approaches and may necessitate an additional and/or an alternative strategy, for instance cell therapy.

\section{Identifying novel targets by gene profiling analysis}

Better understanding of the intimate molecular developmental mechanisms might be achieved by large-scale gene profiling studies. Using this approach, it was determined that corticosteroid-induced septation failure is largely due to angiogenesis blockade consecutive to downregulation of VEGFR2, which was prevented by RA [102]. Comparison of rat lung gene expression before, during and after septation allowed the identification of genes that were upregulated during septation and downregulated thereafter, whereas others were downregulated during septation and upregulated during the step of microvascular maturation and wall thinning [103]. Importantly, septation-impairing treatments down regulated expression in the former group and enhanced expression in the second group, which points out the necessity of a sequential and coordinated control of their expression [103].

In adult mice, a recent study identified genes down regulated by calorie restriction and/or rapidly up regulated after refeeding, two treatments that reduce and increase alveolar number, respectively [104]. The presence of genes encoding proteins (e.g. VEGF, fibulins, RA receptors, MMPs) that have important roles during development is of particular importance because it demonstrates that developmental events and late alveolarization, and hence regeneration, actually share common molecular mechanisms. These findings support the hypothesis that regeneration may be achieved if pathways operative during development could be "rewakened".

\section{Concluding remarks}

Similarities in the pathogenesis of BPD and emphysema are striking. Despite a few specific differences, the mechanisms of lung injury and subsequent molecular cascades involved in one disease are also involved in the other. Most importantly, recent findings indicated that developmental and maintenance programs of alveolar structures share the same signals and pathways. This suggests that emphysema is not solely a destructive process, but is also characterized by impairment of mechanisms devoid to maintenance and repair of alveoli, and that these mechanisms are the same as those impaired in BPD. This allows a variety of molecules identified in these pathways to be considered as potential tools 
and/or targets in the therapeutic objectives of restoring disordered developmental mechanisms, preventing alveolar loss, and hopefully, reinitiating alveolarization mechanisms in the adult lung.

However, some limitations in the conclusions that can be drawn for this comparison however deserve emphasis. Although similar signaling molecules and pathways are relevant for the pathogenesis of both diseases, they should not be assumed to always have the same biological effects, because emphysema occurs in a lung with completed structure whereas BPD occurs in a developing organ. The possibility that maturational differences exist for regulatory molecules and signaling pathways is actually supported by a variety of observations [51, 105, 106]. Consequently, extrapolation of data from experimental models of BPD to emphysema, and reciprocally, should not be assumed systematically and should be independently and accurately tested in each instance. This is crucial to undertake before specific diagnostic or therapeutic approaches can be designed to target either of these diseases.

Nevertheless, the presently available data indicate promising directions. Alleviating the injuries that alter lung parenchymal structures in both diseases is a primary objective. However, this might be insufficient to permit alveolar repair. Although there remain outstanding questions (Box 1), particularly with regard to genetic susceptibility, the recent identification of major players in alveolar development and maintenance make it possible for the first time to consider developing innovative treatments. Retinoids will certainly have a crucial role, although they might be insufficient and will probably require the cooperation of other signaling molecules. Clearly, factors involved in the control of elastic fiber synthesis and microvascular development are essential and should be considered simultaneously. However, because involved regulatory molecules are probably far from being all identified, further basic investigation will be needed to reach a more comprehensive understanding of the control mechanisms of alveolar development.

\section{Disclosure statement}

The authors have no conflict of interest to declare

\section{Acknowledgements}

O.B. was supported by a postdoctoral fellowship grant from the INSER-FRSQ research exchanges.

\section{References}

1. Jobe, H., Bancalari, E. (2001) Bronchopulmonary dysplasia. Am. J. Respir. Crit. Care Med. 163, 1723-1729

2. Baraldi, E., Filippone, M. (2007) Chronic lung disease after premature birth. N. Engl. J. Med. 357, 1946-1955

3. Sharafkhaneh, A. et al. (2008) Pathogenesis of emphysema: from the bench to the bedside. Proc. Am. Thorac. 
Soc. $5,475-477$

4. Kim, V. et al. (2008) New concepts in the pathobiology of chronic obstructive pulmonary disease. Proc. Am. Thorac. Soc. 5, 478-485

5. Bourbon, J. et al. (2005) Control mechanisms of lung alveolar development and their disorders in bronchopulmonary dysplasia. Pediatr. Res. 57, 38R-46R

6. Schittny, J.C. et al. (2008) Evidence and structural mechanism for late lung alveolarization. Am. J. Physiol. Lung Cell. Mol. Physiol. 294, L246-L254

7. Massaro, G.D. et al. (2002) Lung alveoli: endogenous programmed destruction and regeneration. Am. J. Physiol. Lung Cell. Mol. Physiol. 283, L305-L309

8. Fehrenbach, H. et al. (2008) Neoalveolarization contributes to compensatory lung growth following pneumonectomy in mice. Eur. Respir. J. 31, 515-522

9. Saugstad, O.D. (2003) Bronchopulmonary dysplasia-oxidative stress and antioxidants. Semin. Neonatol. 8, 3949.

10. Buch, S. et al. (2000) Changes in expression of platelet-derived growth factor and its receptors in the lungs of newborn rats exposed to air or $60 \% \mathrm{O}_{2}$. Pediatr. Res. 48, 423-433

11. Hosford, G.E., Olson, D.M. (2003) Effects of hyperoxia on VEGF, its receptors, and HIF-2alpha in the newborn rat lung. Am. J. Physiol. Lung Cell. Mol. Physiol. 285, L161-L168

12. Lopez, E. et al. (2006) Nitric oxide donor restores lung growth factor and receptor expression in hyperoxiaexposed rat pups. Am. J. Respir. Cell Mol. Biol. 34, 738-745

13. Rahman, I. et al. (2002) 4-Hydroxy-2-nonenal, a specific lipid peroxidation product, is elevated in lungs of patients with chronic obstructive pulmonary disease. Am. J. Respir. Crit. Care Med. 166, 490-495

14. Montuschi, P. et al. (2000) Exhaled 8-isoprostane as an in vivo biomarker of lung oxidative stress in patients with COPD and healthy smokers. Am. J. Respir. Crit. Care Med. 162, 1175-1177

15. Maestrelli, P. et al. (2003) Decreased haem oxygenase-1 and increased inducible nitric oxide synthase in the lung of severe COPD patients. Eur. Respir. J. 21, 971-976

16. Speer, C.P. (2006) Inflammation and bronchopulmonary dysplasia: a continuing story. Semin. Fetal Neonatal Med. 11, 354-62

17. Auten, R.L., Jr et al. (2001) Anti-neutrophil chemokine preserves alveolar development in hyperoxia-exposed newborn rats. Am. J. Physiol. Lung Cell. Mol. Physiol. 281, L336-L344

18. Baier, R.J. et al. (2003) Interleukin-4 and 13 concentrations in infants at risk to develop Bronchopulmonary Dysplasia. BMC Pediatr. 3, 8

19. Boutten, A. et al. (2004) Decreased expression of interleukin 13 in human lung emphysema. Thorax 59, 850854

20. Altiok, O. et al. (2006) Imbalance between cysteine proteases and inhibitors in a baboon model of bronchopulmonary dysplasia. Am. J. Respir. Crit. Care Med. 173, 318-326

21. Finkelstein, R. et al. (1995) Alveolar inflammation and its relation to emphysema in smokers. Am. J. Respir. Crit. Care Med. 152, 1666-1672

22. Ohnishi, K. et al. (1998) Matrix metalloproteinase-mediated extracellular matrix protein degradation in human pulmonary emphysema. Lab. Invest. 78, 1077-1087

23. Hautamaki, R.D. et al. (1997) Requirement for macrophage elastase for cigarette smoke-induced emphysema in mice. Science $277,2002-2004$

24. Danan, C. et al. (2002) Gelatinase activities in the airways of premature infants and development of bronchopulmonary dysplasia. Am. J. Physiol. Lung Cell. Mol. Physiol. 283, L1086-L1093

25. Ekekezie, I.I. et al. (2004) Low levels of tissue inhibitors of metalloproteinases with a high matrix metalloproteinase-9/tissue inhibitor of metalloproteinase-1 ratio are present in tracheal aspirate fluids of infants who develop chronic lung disease. Pediatrics 113, 1709-1714

26. Chetty, A. et al. (2008) Role of matrix metalloprotease-9 in hyperoxic injury in developing lung. Am. J. Physiol. Lung Cell. Mol. Physiol. 295, L584-L592

27. Lukkarinen, H. et al. (2008) Matrix Metalloproteinase-9 deficiency worsens lung injury in a model of bronchopulmonary dysplasia. Am. J. Respir. Cell Mol. Biol. Dec 18. [Epub ahead of print]

28. Atkinson, J.J. et al. (2005) Membrane-type 1 matrix metalloproteinase is required for normal alveolar development. Dev. Dyn. 232, 1079-1090

29. Hadchouel, A. et al. (2008) Matrix metalloproteinase gene polymorphisms and bronchopulmonary dysplasia: identification of MMP16 as a new player in lung development. PLOS ONE 3, e3188

30. Hargitai, B. et al. (2001) Apoptosis in various organs of preterm infants: histopathologic study of lung, kidney, liver, and brain of ventilated infants. Pediatr. Res. 50, 110-114

31. Imai, K. et al. (2005) Correlation of lung surface area to apoptosis and proliferation in human emphysema. Eur. Respir. J. 25, 250-258

32. Petrache, I. et al. (2005) Ceramide upregulation causes pulmonary cell apoptosis and emphysema-like disease in mice. Nat. Med. 11, 491-498

33. Tsuji, T. et al. (2006) Alveolar cell senescence in patients with pulmonary emphysema. Am. J. Respir. Crit. Care Med. 174, 886-893

34. Shifren, A. Mecham, R.P. (2006) The stumbling block in lung repair of emphysema: elastic fiber assembly. Proc. Am. Thorac. Soc. 3, 428-433

35. Bruce, M.C et al. (1992) Risk factors for the degradation of lung elastic fibers in the ventilated neonate. Implications for impaired lung development in bronchopulmonary dysplasia. Am. Rev. Respir. Dis. 146, $204-212$ 36. Le Cras, T.D. et al. (2004) Transient induction of TGF-alpha disrupts lung morphogenesis, causing pulmonary 
disease in adulthood. Am. J. Physiol. Lung Cell. Mol. Physiol. 287, L718-L729

37. Bland, R.D. et al. (2008) Mechanical ventilation uncouples synthesis and assembly of elastin and increases apoptosis in lungs of newborn mice. Prelude to defective alveolar septation during lung development? Am. J. Physiol. Lung Cell. Mol. Physiol. 294, L3-L14

38. Gottlieb, D.J. et al. (1996) Urinary desmosine excretion in smokers with and without rapid decline of lung function: the Normative Aging Study. Am. J. Respir. Crit. Care Med. 154, 1290-1295

39. Shifren, A. et al. (2007) Elastin protein levels are a vital modifier affecting normal lung development and susceptibility to emphysema. Am. J. Physiol. Lung Cell. Mol. Physiol. 292, L778-L787

40. Mäki, J.M. et al. (2005) Lysyl oxidase is essential for normal development and function of the respiratory system and for the integrity of elastic and collagen fibers in various tissues. Am. J. Pathol. 167, 927-936

41. Neptune, E.R. et al. (2003) Dysregulation of TGF- $\beta$ activation contributes to pathogenesis in Marfan syndrome. Nat. Genet. 33, 407-411

42. Yanagisawa, H. et al. (2002) Fibulin-5 is an elastin-binding protein essential for elastic fibre development in vivo. Nature $415,168-171$

43. van Houwelingen, A.H. et al. (2008) Induction of lung emphysema is prevented by L-arginine-threoninearginine. FASEB J. 22, 3403-3408

44. Stenmark, K.R., Abman, S.H. (2005) Lung vascular development: implications for the pathogenesis of bronchopulmonary dysplasia. Annu. Rev. Physiol. 67, 623-661

45. McGrath-Morrow, S.A. et al. (2005) Vascular endothelial growth factor receptor 2 blockade disrupts postnatal lung development. Am. J. Respir. Cell Mol. Biol. 32, 420-427

46. Kasahara, Y. et al. (2000) Inhibition of VEGF receptors causes lung cell apoptosis and emphysema. J. Clin. Invest. 106, 1311-1319

47. Tang, K. et al. (2004) Lung-targeted VEGF inactivation leads to an emphysema phenotype in mice. J. Appl. Physiol. 97, 1559-1566

48. Kasahara, Y. et al. (2001) Endothelial cell death and decreased expression of vascular endothelial growth factor and vascular endothelial growth factor receptor 2 in emphysema. Am. J. Respir. Crit. Care Med. 163, 737744

49. Bhatt, A.J. et al. (2001) Disrupted pulmonary vasculature and decreased vascular endothelial growth factor, Flt-1, and TIE-2 in human infants dying with bronchopulmonary dysplasia. Am. J. Respir. Crit. Care Med. 164, 1971-1980

50. De Paepe, M.E. et al. (2006) Growth of pulmonary microvasculature in ventilated preterm infants. Am. J. Respir. Crit. Care Med. 173, 204-211

51. Bhandari, V. et al. (2008) Developmental regulation of NO-mediated VEGF-induced effects in the lung. Am J. Respir Cell Mol Biol. 39, 420-430

52. Kallapur, S.G. et al. (2004) Vascular changes after intra-amniotic endotoxin in preterm lamb lungs. Am. J. Physiol. Lung Cell Mol. Physiol. 287, L1178-L1185

53. Bland, R.D. et al. (2007) Mechanical ventilation with $40 \%$ oxygen reduces pulmonary expression of genes that regulate lung development and impairs alveolar septation in newborn mice. Am. J. Physiol. Lung Cell. Mol. Physiol. 293, L1099-L1110

54. Thébaud, B. et al. (2005) Vascular endothelial growth factor gene therapy increases survival, promotes lung angiogenesis, and prevents alveolar damage in hyperoxia-induced lung injury: evidence that angiogenesis participates in alveolarization. Circulation 112, 2477-2486

55. Le Cras, T.D., et al. (2004) VEGF causes pulmonary hemorrhage, hemosiderosis, and air space enlargement in neonatal mice. Am. J. Physiol. Lung Cell. Mol. Physiol. 287, L134-L142

56. Janér, J. et al. (2007) Pulmonary endostatin perinatally and in lung injury of the newborn infant. Pediatrics 119: e241-246

57. Bhandari, V. et al. (2006) Hyperoxia causes angiopoietin 2-mediated acute lung injury and necrotic cell death. Nat. Med. 12, 1286-1293

58. Aghai, Z.H. et al. (2008) Angiopoietin 2 concentrations in infants developing bronchopulmonary dysplasia: attenuation by dexamethasone. J. Perinatol. 28, 149-155

59. De Paepe, M.E. et al. (2008) Endoglin (CD105) up-regulation in pulmonary microvasculature of ventilated preterm infants. Am. J. Respir. Crit. Care Med. 178, 180-187

60. Wong, P.M. et al. (2008) Emphysema in young adult survivors of moderate to severe bronchopulmonary dysplasia. Eur. Respir. J. 32, 321-328

61. Shinwell, E.S. et al. (2007) Less postnatal steroids, more bronchopulmonary dysplasia: a population-based study in very low birthweight infants. Arch. Dis. Child. Fetal Neonatal Ed. 92, F30-F33

62. Bland, R.D. et al. (2005) Inhaled nitric oxide effects on lung structure and function in chronically ventilated preterm lambs. Am. J. Respir. Crit. Care Med. 172, 899-906

63. Barrington, K.J., Finer, N.N. (2007) Inhaled nitric oxide for respiratory failure in preterm infants. Cochrane Database Syst. Rev. (3): CD000509

64. Lauterbach, R. et al. (2006) Nebulized pentoxifylline for prevention of bronchopulmonary dysplasia in very low birth weight infants: a pilot clinical study. J. Matern. Fetal Neonatal Med. 19, 433-438

65. Liao, L. et al. (2006) CXCR2 blockade reduces radical formation in hyperoxia-exposed newborn rat lung. Pediatr. Res. 60, 299-303

66. Motterlini, R. et al. (2000) Curcumin, an antioxidant and anti-inflammatory agent, induces heme oxygenase-1 and protects endothelial cells against oxidative stress. Free Radic. Biol. Med. 28, 1303-1312

67. Takahashi, S. et al. (2008) Reversal of elastase-induced pulmonary emphysema and promotion of alveolar 
epithelial cell proliferation by simvastatin in mice. Am. J. Physiol. Lung Cell. Mol. Physiol. 294, L882-L890

68. Morimoto, K. et al. (2006) Lovastatin enhances clearance of apoptotic cells (efferocytosis) with implications for chronic obstructive pulmonary disease. J. Immunol. 176, 7657-7665

69. Shinohara, T. et al. (2005) Adenovirus-mediated transfer and overexpression of heme oxygenase $1 \mathrm{cDNA}$ in lungs attenuates elastase-induced pulmonary emphysema in mice. Hum. Gene Ther. 16, 318-327

70. de Visser, Y.P. et al. (2008) Phosphodiesterase 4 inhibition attenuates pulmonary inflammation in neonatal lung injury. Eur. Respir. J. 31, 633-644

71. Méhats, C. et al. (2008) Effects of phosphodiesterase 4 inhibition on alveolarization and hyperoxia toxicity in newborn rats. PLoS ONE. 2008;3(10):e3445

72. Mori, H. et al. (2008) Phosphodiesterase 4 inhibitor (GPD-1116) markedly attenuates the development of cigarette smoke-induced emphysema in senescence accelerated mice P1 strain. Am. J. Physiol. Lung Cell. Mol. Physiol. 294, L196-L204

73. Martorana, P.A. et al. (2005) Roflumilast fully prevents emphysema in mice chronically exposed to cigarette smoke. Am. J. Respir. Crit. Care Med. 172, 848-853

74. Ladha, F. et al. (2005) Sildenafil improves alveolar growth and pulmonary hypertension in hyperoxia-induced lung injury. Am. J. Respir. Crit. Care Med. 172, 750-756

75. Petrache, I. et al. (2006) A novel antiapoptotic role for alpha1-antitrypsin in the prevention of pulmonary emphysema. Am. J. Respir. Crit. Care Med. 173, 1222-1228

76. Churg, A. et al. (2007) Effect of an MMP-9/MMP-12 inhibitor on smoke-induced emphysema and airway remodelling in guinea pigs. Thorax $62,706-713$

77. Massaro, G.D., Massaro, D. (1996) Postnatal treatment with retinoic acid increases the number of pulmonary alveoli in rats. Am. J. Physiol. Lung Cell. Mol. Physiol. 270, L305-L310

78. McGowan, S. et al. (2000) Mice bearing deletions of retinoic acid receptors demonstrate reduced lung elastin and alveolar numbers. Am. J. Respir. Cell Mol. Biol. 23, 162-167

79. Spears, K. et al. (2004) Low plasma retinol concentrations increase the risk of developing bronchopulmonary dysplasia and long-term respiratory disability in very-low-birth-weight infants. Am. J. Clin. Nutr. 80, 1589-1594 80. Morabia, A. et al. (1990) Serum retinol and airway obstruction. Am. J. Epidemiol. 132, 77-82

81. Massaro, G.D., Massaro, D. (2000) Retinoic acid treatment partially rescues failed septation in rats and in mice. Am. J. Physiol. Lung Cell. Mol. Physiol. 278, L955-L960

82. Veness-Meehan, K.A. et al. (2002) Retinoic acid attenuates $\mathrm{O}_{2}$-induced inhibition of lung septation. Am. J. Physiol. Lung Cell. Mol. Physiol. 283, L971-L980

83. Cho, S.J., et al. (2005) Retinoic acid and erythropoietin maintain alveolar development in mice treated with an angiogenesis inhibitor. Am. J. Respir. Cell Mol. Biol. 33, 622-628

84. Massaro, G.D., Massaro, D. (1997) Retinoic acid treatment abrogates elastase-induced pulmonary emphysema in rats. Nat. Med. 3, 675-677

85. Fujita, M. et al. (2004) Retinoic acid fails to reverse emphysema in adult mouse models. Thorax 59, 224-230

86. Pierce, R.A. et al. (2007) Retinoids increase lung elastin expression but fail to alter morphology or angiogenesis genes in premature ventilated baboons. Pediatr. Res. 61, 703-709

87. Darlow, B.A., Graham, P.J. (2007) Vitamin A supplementation to prevent mortality and short and long-term morbidity in very low birthweight infants. Cochrane Database Syst. Rev. (4): CD000501.

88. Roth, M.D. et al.; FORTE Study Investigators. (2006) Feasibility of retinoids for the treatment of emphysema study. Chest $130,1334-1345$

89. Muindi, J.R. et al.; for the FORTE Study Investigators. (2008) Pharmacokinetics and Metabolism of All-transand 13-cis-Retinoic Acid in Pulmonary Emphysema Patients. J. Clin. Pharmacol. 48, 96-107

90. Plantier, L. et al. (2008) Dysregulation of elastin expression by fibroblasts in pulmonary emphysema: Role of Cellular Retinoic Acid Binding Protein 2. Thorax 63, 1012-1017

91. Yan, X. et al. (2004) Retinoic acid induces nonuniform alveolar septal growth after right pneumonectomy. J. Appl. Physiol. 96, 1080-1089

92. Lindahl, P. et al. (1997) Alveogenesis failure in PDGF-A-deficient mice is coupled to lack of distal spreading of alveolar smooth muscle cell progenitors during lung development. Development 124, 3943-3953

93. Padela, S. et al. (2005) Hepatocyte growth factor is required for alveologenesis in the neonatal rat. Am. J. Respir. Crit. Care Med. 172, 907-914

94. Weinstein, M. et al. (1998) FGFR-3 and FGFR-4 function cooperatively to direct alveogenesis in the murine lung. Development 125, 3615-3623

95. Chailley-Heu, B. et al. (2005) FGF-18 is up-regulated in the postnatal rat lung and enhances elastogenesis in myofibroblasts. Am. J. Physiol. Lung Cell. Mol. Physiol. 288, L43-L51

96. Danan, C. et al. (2002) High concentrations of keratinocyte growth factor in airways of premature infants predicted absence of bronchopulmonary dysplasia. Am. J. Respir. Crit. Care Med. 165, 1384-1387

97. Plantier, L. et al. (2005) Defect of hepatocyte growth factor production by fibroblasts in human pulmonary emphysema. Am. J. Physiol. Lung. Cell. Mol. Physiol. 288, L641-L647

98. Frank, L. (2003) Protective effect of keratinocyte growth factor against lung abnormalities associated with hyperoxia in prematurely born rats. Biol. Neonate $83,263-272$

99. Ohki, Y. et al. (2008) Hepatocyte growth factor treatment improves alveolarization in a newborn murine model of bronchopulmonary dysplasia. Neonatology 95, 332-338

100. Shigemura, N. et al. (2005) Amelioration of pulmonary emphysema by in vivo gene transfection with hepatocyte growth factor in rats. Circulation 111, 1407-1414

101. Plantier, L. et al. (2007) Keratinocyte growth factor protects against elastase-induced pulmonary emphysema 
in mice. Am. J. Physiol. Lung Cell. Mol. Physiol. 293, L1230-L1239

102. Clerch, L.B. et al. (2004) DNA microarray analysis of neonatal mouse lung connects regulation of KDR with dexamethasone-induced inhibition of alveolar formation. Am. J. Physiol. Lung Cell. Mol. Physiol. 286, L411-L419 103. Boucherat, O. et al. (2007) Gene expression profiling in lung fibroblasts reveals new players in alveolarization. Physiol. Genomics 32, 128-141

104. Massaro, D. et al. (2007) Rapid onset of gene expression in lung, supportive of formation of alveolar septa, induced by refeeding mice after calorie restriction. Am. J. Physiol. Lung Cell. Mol. Physiol. 292, L1313-L1326

105. Yang, G. et al. (2004) Maturational differences in lung NF-kappaB activation and their role in tolerance to hyperoxia. J. Clin. Invest. 114, 669-678

106. Rayman, C.W. et al. (2007) Developmental differences in the responses of IL-6 and IL-13 transgenic mice exposed to hyperoxia. Am. J. Physiol. Lung Cell. Mol. Physiol. 293: L142-L150

107. Ghanei, M. and harandi, A.A. (2007) Long term consequences of for exposure to sulfur mustard: a review. Inhal. Toxicol. 19, 451-456

108. March, T.H. et al. (2000) Animal models of emphysema and their relevance to studies of particle-induced diseases. Inhal. Toxicol. 12 (Suppl. 4), 155-187

109. Shapiro, S.D. (2003) Proteolysis in the lung. Eur. Respir. J. 22 (Suppl. 44), 30s-32s

110. Cataldo, D. et al. (2000) MMP-2 and MMP-9-linked gelatinolytic activity in the sputum of patients with asthma and chronic obstructive pulmonary disease. Int. Arch. Allergy Immunol. 123, 259-267

(a)

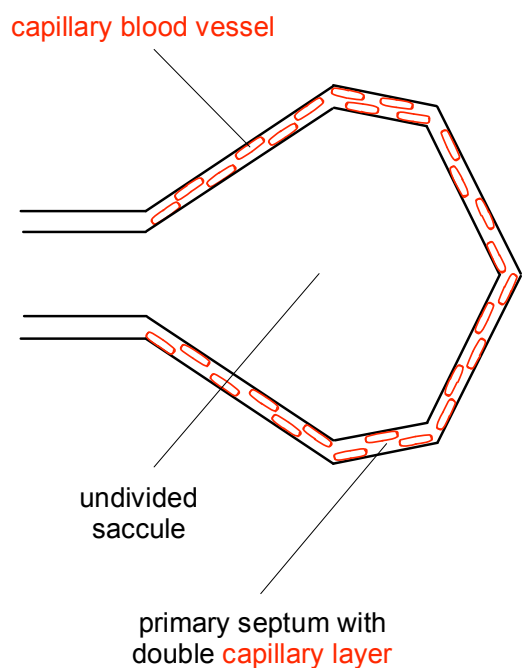

(b)

secondary septa with single capillary layer and elastic fibers at tip

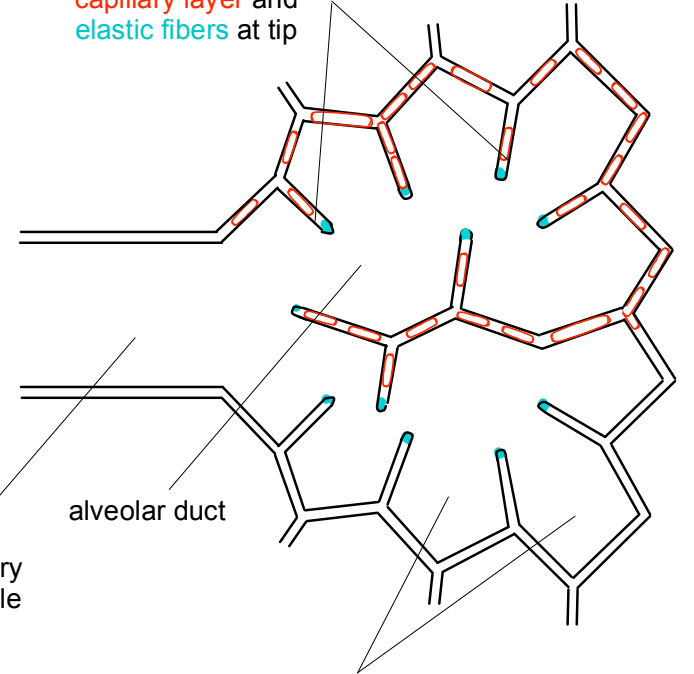

definitive alveoli

Figure 1. Schematic representation of saccular (a) and alveolar (b) structures. Air-blood barriers that allow respiratory gases to diffuse are formed by tight apposition of capillary endothelium to saccular/alveolar epithelium (for simplification, vessels have been represented in only one half of the alveolar picture). The alveolarization process (arrow) consists of (i) the subdivision of saccular air space by surge and growth of secondary septa, which leads to considerable increase of exchange surface area, and (ii) the maturation of septa with fusion of capillary vessels into a single central layer and thinning of septa. In the human lung, alveolar formation starts during the last gestational weeks, but at full-term birth, the lung is still mostly comprised of undivided saccules, and the process extends at least over the first two postnatal years. VLBW premature infants are born with a lung in late-canalicular (previous stage preceding saccule formation that marks the absolute limit of viability with formation of the first air-blood barriers) or early-saccular stage. 


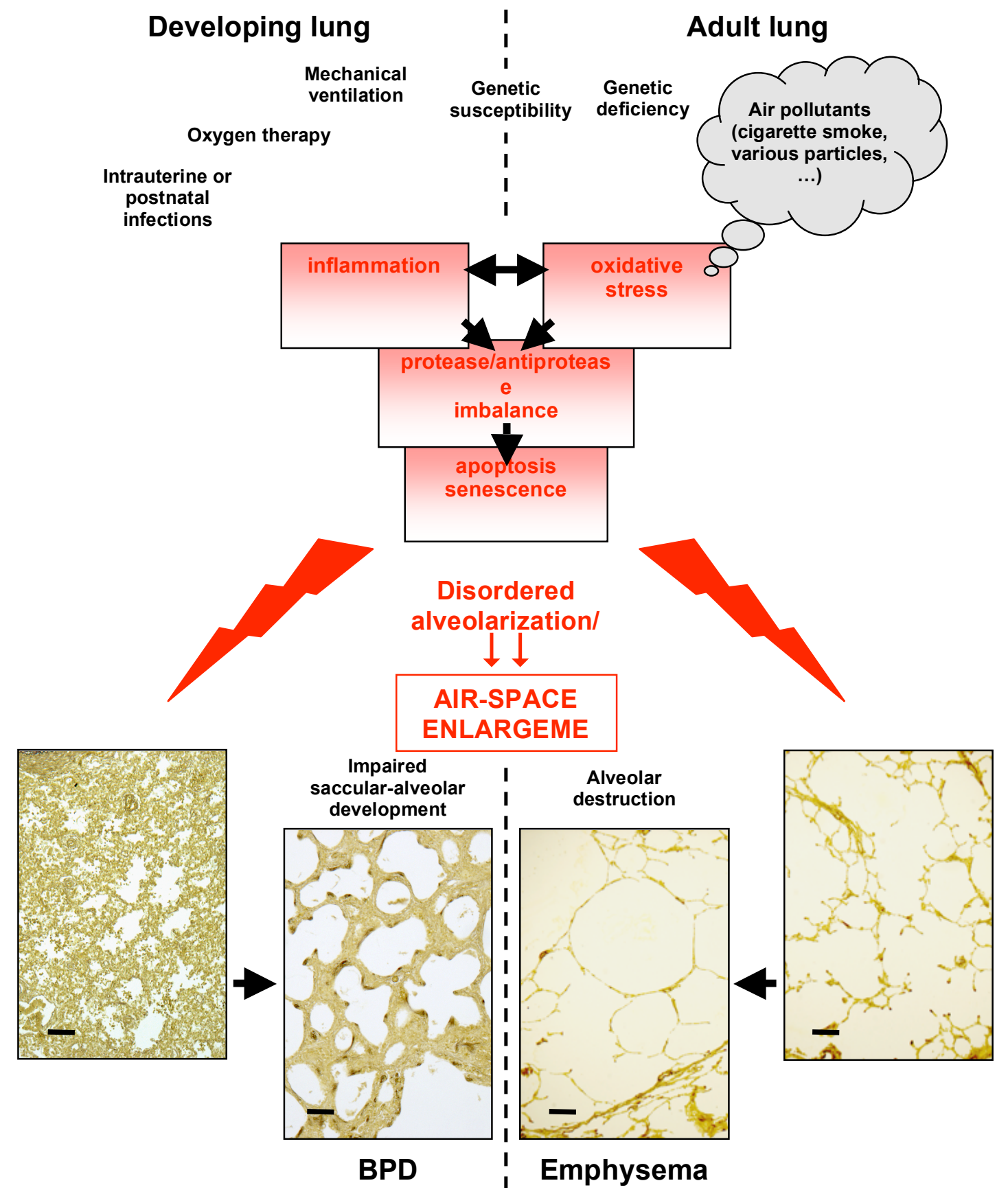

Figure 2. Integration of pathogenic mechanisms in bronchopulmonary dysplasia (BPD) and emphysema. The respective leading causes of each disease induce common consequences, including oxidative stress and inflammation, which in turn cause protease/antiprotease imbalance, apoptosis and/or cell senescence. This results in impairment of alveolar developmental (BPD) or maintenance (emphysema) programs, including development and/or stability of elastic fibers and the microvascular network, leading to paucity of alveolar septa and airspace enlargement. The doted line separates specific features of each of the diseases; medial position of text or interruption of the line at the level of pathogenic mechanisms indicates features shared by the diseases. Original light-microscopy pictures from O.B.: 5- $\mu \mathrm{m}$-thick paraffin sections of lung parenchyma from autopsy specimens (developing lungs) or surgical resections (adult lungs). Lung tissue was stained with Hart's resorcinfuchsin stain for elastin and counterstained with tartrazine. The final magnification is the same for all four pictures (scale bars represent $200 \mu \mathrm{m}$ ). Normal developing and adult lungs are shown on the far lest and far right, respectively. 


\section{Glossary}

Acinus: the morphofunctional unit of the lung constituted by the alveolar channels, alveolar sacs and alveoli originating from a same respiratory bronchiole.

Alveolus: anatomical structure of the lung forming a hollow cavity that represents the smallest unit structure of pulmonary parenchyma. Neighbor alveoli share the same walls. There are 300 to 500 million alveoli in the adult human lung (but at most 50 million of alveoli and undivided saccules at birth) for a total surface area of about $100 \mathrm{~m}^{2}$ of which capillary vessels (air-blood barriers) cover about $70 \%$.

Apoptosis: programmed cell death. A process that involves a series of biochemical events (notably activation of the degrading enzymes caspases) and cell morphological changes, including blebbing, membrane detachment, and characteristic nuclear and DNA fragmentation. Contrary to necrosis, which represents traumatic cell death from acute injury, apoptosis does not induce inflammatory reaction. Apoptosis is a normal process in living organisms, but which can be pathologically enhanced.

CXC chemokines: regulatory peptides in which the two N-terminal cysteines (C) are separated by one aminoacyl residue, represented in this name by $X$.

Cytokines: diffusible signaling molecules (proteins, peptides, or glycoproteins) used in cellular communication. The term historically designated (and is still often used restrictively to designate) immunomodulating agents (interleukins [ILs], tumor necrosis factors [TNFs], interferons, etc.), although it can apply to other mediators.

Elastase: an enzyme that breaks elastin and collagen. In humans, there are two elastase genes that encode pancreatic elastase and neutrophil elastase, respectively.

Elastic fibers: complex extracellular microscopic structures comprised of a scaffold of microfibrillar proteins onto which the elastic protein elastin is polymerized from its soluble precursor tropoelastin.

Extracellular matrix (ECM): the extracellular part of tissues providing structural support to cells. It is composed of specific proteins (collagens, elastin, fibronectins, laminins, etc.) and proteoglycans (carbohydrate and protein combination). ECM includes interstitial matrix (connective tissues) and basement membranes (or basal laminae, beneath epithelia).

Fibrosis: pathological development of excess fibrous connective tissue and excess proliferation of interstitial cells (fibroblasts). In the lung, fibrosis may be idiopathic or associated with other pathological processes.

Growth factors: diffusible mediators of cell-cell interactions (naturally occurring proteins or peptides) capable of stimulating cell proliferation and differentiation.

Macrophages: resident phagocytic cells. They derivate from circulating monocytes (white blood cells). Contrary to polymorphonuclear neutrophils, they are present in the healthy alveolus in the absence of inflammation.

Matrix metalloproteinases (MMPs): zinc-dependent, secreted or membrane-linked enzymes (endopeptidases) belonging to the metzincin superfamily. They are capable of degrading all kinds of extracellular matrix proteins but are also known to cleave cell-surface receptors, to release apoptotic ligands and cytokines/chemokines, and to activate/inactivate the latter. They are involved in control of cell proliferation, migration, differentiation, angiogenesis, apoptosis and host defense.

Polymorphonuclear neutrophils (PMNs): the most common type of granulocytes (or granular leukocytes, the most abundant white blood cells characterized by the presence of secretory granules in the cytoplasm). PMNs are able to perform phagocytosis and to release cytokines; they invade tissues during inflammatory reaction.

Proteases: enzymes (naturally occurring proteins) able to perform protein degradation (proteolysis). There exists a great variety of proteases.

Respiratory distress syndrome (RDS): acute respiratory disease of the neonatal infant with immediate onset, caused by lung surfactant deficiency. It results most often from premature delivery and is combated by exogenous surfactant and mechanical ventilation with possibly increased inspired oxygen fraction (also known as hyaline membrane disease).

Retinoids: a family of molecules comprising vitamin A (retinol and retinyl esters) and its active metabolites retinal (involved in vision), and the various isoforms of retinoic acid (RA). RA binds specific receptors in cell cytoplasm, and the formed complex is translocated then to the nucleus, where it acts as a transcription factor through binding to specific DNA regulatory sequences.

Tissue inhibitors of metalloproteinases (TIMPs): four naturally occurring specific inhibitors of MMPs. The rate of extracellular matrix remodeling depends on the balance between MMP and TIMP activities. 


\section{Box 1. Outstanding questions}

\section{Genetic susceptibility}

BPD and emphysema do not occur in all VLBW infants or in all smokers, respectively, despite the presence of similar circumstances. There is growing evidence that the risk of developing these diseases is largely dependent on genetic susceptibility, and various gene polymorphisms are suspected to be involved. This aspect should be documented further to better identify at-risk subjects and to develop more efficient preventive approaches and treatments.

\section{Developmental vs maintenance programs}

As shown in this review, it is now established that the alveolar development and maintenance programs share a number of molecules and pathways, but it is not fully understood whether these have precisely the same biological effects in the developing and adult lung. The existence of specific differences, suggested by recent findings, should be explored further before trying to define new common therapeutic strategies in these diseases.

\section{Relative inefficiency of retinoids}

Despite the considerable amount of experimental data supporting the central role of retinoic acid in triggering alveolar development and maintaining alveolar structure, clinical trials using retinoids have been rather disappointing. The reasons are probably multiple (nature and biological availability of the used molecules, protocol and route of delivery, deficit in binding proteins or receptors, multifactorial control of biological mechanisms, difficulty to reinitiate coordinated production of elastic fiber components and fiber assembly, etc.), and better understanding these represents a challenge to optimize the therapeutic use of retinoids. 
Table 1. Summary of similarities and differences between known cellular and molecular pathophysiological mechanisms in bronchopulmonary dysplasia (BPD) and emphysema ${ }^{a}$

\begin{tabular}{|c|c|c|c|c|}
\hline & & BPD & Emphysema & References \\
\hline Leading causes & Oxidative stress & + & + & $\begin{array}{c}{[1,3,4,8} \\
12,13]\end{array}$ \\
\hline & $\begin{array}{l}\text { Inhaled toxic substances } \\
\text { or particles }\end{array}$ & - & + & {$[107,108]$} \\
\hline & Mechanical injury & + & \pm & {$[1,4]$} \\
\hline & Infections & \pm & - & [1] \\
\hline & $\begin{array}{l}\text { Directly associated genetic } \\
\text { disorders }\end{array}$ & - & + & [3] \\
\hline & $\begin{array}{l}\text { Risk-associated gene } \\
\text { polymorphisms }\end{array}$ & + & + & [2] \\
\hline Histological features & Airspace enlargement & + & + & [1-4] \\
\hline & $\begin{array}{l}\text { Elastic fiber destruction/ } \\
\text { disrupted assembly }\end{array}$ & + & + & [37-41] \\
\hline & Extracellular matrix remodeling & + & + & [1-4] \\
\hline & Diminished microvasular bed & \pm & + & {$[52-54]$} \\
\hline & Dysmorphic capillary vessels & + & - & $1,52-54$ \\
\hline & Interstitial fibrosis & \pm & - & {$[1,4]$} \\
\hline $\begin{array}{l}\text { Inflammatory } \\
\text { process }\end{array}$ & $\begin{array}{l}\text { Alveolar recruitment of } \\
\text { Neutrophils/Macrophages }\end{array}$ & + & + & {$[16,18,19]$} \\
\hline & $\begin{array}{l}\text { Increased pro-inflammatory } \\
\text { cytokines/chemokines }\end{array}$ & + & + & {$[4,16]$} \\
\hline & $\begin{array}{l}\text { Decreased anti-inflammatory } \\
\text { cytokines }\end{array}$ & + & + & {$[20,21]$} \\
\hline $\begin{array}{l}\text { Protease/anti- } \\
\text { protease imbalance }\end{array}$ & $\begin{array}{l}\text { Increased neutrophil elastase } \\
\text { and cathepsins }\end{array}$ & + & \pm & {$[19,22,109]$} \\
\hline & $\begin{array}{l}\text { Increased MMP }(1,2,9,12, \ldots) \\
\text { activity }\end{array}$ & + & + & $\begin{array}{c}{[23,25,26} \\
109]\end{array}$ \\
\hline & Decreased TIMP $(1,3)$ activity & + & + & {$[26,110]$} \\
\hline Cell death and & Apoptosis & + & + & {$[31,32]$} \\
\hline & Accelerated cell senescence & $?$ & + & {$[34,35]$} \\
\hline Altered signaling/ & Retinoid insufficiency & + & \pm & {$[87,88]$} \\
\hline & $\begin{array}{l}\text { Disturbed expression of growth } \\
\text { factors (VEGF and angiogenic } \\
\text { regulators, FGFs, HGF,...) }\end{array}$ & + & + & $\begin{array}{c}52,53,55 \\
60,62,63 \\
101,102] \\
\end{array}$ \\
\hline
\end{tabular}

\footnotetext{
${ }^{a}+$ indicates presence, - indicates absence, \pm indicates mild character or variability
} 
Table 2. Principal pharmacological strategies used to attempt preventing or reversing airspace enlargement and associated disorders in BPD, emphysema, or their animal models.

\begin{tabular}{|c|c|c|c|c|}
\hline \multirow{2}{*}{ TREATMENTS } & \multicolumn{2}{|c|}{ in BPD or models } & \multicolumn{2}{|c|}{ in Emphysema models } \\
\hline & Positive effects & $\begin{array}{c}\text { Absence of } \\
\text { effects } \\
\text { or adverse effects }\end{array}$ & Positive effects & $\begin{array}{l}\text { Absence of } \\
\text { effects }\end{array}$ \\
\hline $\begin{array}{l}\text { Inhaled Nitric Oxide (NO) and } \\
\text { NO donors }\end{array}$ & $\begin{array}{l}\text { NO donor in } \\
\text { hyperoxia-exposed } \\
\text { rats: on mediator } \\
\text { expression [12] } \\
\text { NO in preterm lamb } \\
\text { [62] }\end{array}$ & \begin{tabular}{|l|} 
NO donor in \\
hyperoxia-exposed \\
rats: on alveolar \\
septation [12] \\
\\
NO, adverse \\
effects in VLBW \\
infants [63]
\end{tabular} & Unknown & Unknown \\
\hline $\begin{array}{l}\text { Anti-inflammatory approaches } \\
\text { (chemokine antagonists) } \\
\text { and } \\
\text { Anti-oxidant approaches } \\
\text { (curcumin, statins, HO1) }\end{array}$ & $\begin{array}{l}\text { antichemokine or } \\
\text { receptor blockade in } \\
\text { hyperoxia-exposed } \\
\text { rats }[17,65] \\
\text { pentoxyfilline in } \\
\text { VLBW infants[64] }\end{array}$ & $\begin{array}{l}\text { No adverse effects } \\
\text { observed }\end{array}$ & $\begin{array}{l}\text { inhibitory peptide in } \\
\text { mouse model [43] } \\
\text { curcumin [66], } \\
\text { simvastatin [67], } \\
\text { lovastatin [68], or } \\
\text { HO-1 [69] in mouse } \\
\text { models }\end{array}$ & Unknown \\
\hline Protease inhibitors & Unknown & Unknown & $\begin{array}{l}\text { MMP inhibitor in } \\
\text { guinea pig model } \\
{[76]}\end{array}$ & Unknown \\
\hline Phosphodiesterase inhibitors & $\begin{array}{l}\text { rolipram or } \\
\text { piclamilast in } \\
\text { hyperoxia-exposed } \\
\text { rats: on } \\
\text { inflammation } \\
{[70,71]} \\
\text { sildenafil in } \\
\text { hyperoxia-exposed } \\
\text { rats [74], }\end{array}$ & $\begin{array}{l}\text { rolipram in } \\
\text { hyperoxia-exposed } \\
\text { rats: on alveolar } \\
\text { septation [71] }\end{array}$ & $\begin{array}{l}\text { GPD-1116 [72] or } \\
\text { roflumilast [73] in } \\
\text { mouse models }\end{array}$ & Unknown \\
\hline $\begin{array}{l}\text { Ceramide synthesis inhibitor } \\
\text { and ceramide inhibition }\end{array}$ & Not tested & Not tested & $\begin{array}{l}\text { fumonisin } \mathrm{B} 1, \\
\text { myriocin, } \\
\text { sphingosine-1P } \\
\text { analog, and } \\
\text { ceramide- } \\
\text { neutralizing antibody } \\
\text { in mouse model [32] }\end{array}$ & Unknown \\
\hline Retinoids & $\begin{array}{l}\text { RA in hyperoxic } \\
\text { model in rats [82] } \\
\text { RA in angiogenic } \\
\text { inhibition in mice } \\
\text { [83] }\end{array}$ & $\begin{array}{l}\text { vitamin A in } \\
\text { premature } \\
\text { baboons [86] }\end{array}$ & $\begin{array}{l}\text { RA in rats and mice } \\
\text { with or without } \\
\text { inhibited alveolar } \\
\text { septation }[77,81]\end{array}$ & $\begin{array}{l}\text { RA in mouse } \\
\text { models [85] }\end{array}$ \\
\hline $\begin{array}{l}\text { Growth factor } \\
\text { supplementation }\end{array}$ & $\begin{array}{l}\text { VEGF [54] or } \\
\text { FGF7 [98] in } \\
\text { hyperoxia-exposed } \\
\text { rats } \\
\text { HGF [99] or } \\
\text { EPO [83] in mouse } \\
\text { models }\end{array}$ & $\begin{array}{l}\text { VEGF injurious in } \\
\text { mouse prenatal } \\
\text { lung [51] }\end{array}$ & $\begin{array}{l}\text { FGF7 in mouse } \\
\text { model, preventive } \\
{[101]} \\
\text { HGF in rats [100] }\end{array}$ & $\begin{array}{l}\text { FGF7 in mouse } \\
\text { model, curative } \\
{[101]}\end{array}$ \\
\hline
\end{tabular}

